ARTICLE

https://doi.org/10.1057/s41599-019-0297-7

\title{
Risk perception of arsenic exposure from rice intake in a UK population
}

\author{
Debapriya Mondal (1) ${ }^{1}$, Tasila Mwale ${ }^{1}$, Lingqian Xu ${ }^{2}$, Helen Matthews ${ }^{3}$, Anuli Oyeka ${ }^{1}$, Gemma Lace-Costigan ${ }^{1} \&$ \\ David A. Polya ${ }^{2}$
}

\begin{abstract}
In the UK, consumption of rice and rice-based products is on the rise but, notwithstanding public expressed concerns about such products as an exposure route for arsenic (e.g., BBC News report, 2017 'Should I worry about arsenic in my rice?') there are few, if any published data on public perceptions of risks associated with exposure to arsenic in rice. We therefore aimed to determine the risk perception of arsenic exposure from rice intake and factors that are associated with arsenic knowledge and whether or not this knowledge had an influence on rice consumption and cooking practices. A questionnaire, targeting participation of rice-eating ethnic minorities in Greater Manchester, UK, was administered to 184 participants. A multivariate generalised linear model was used to determine the factors associated with rice consumption behaviour, cooking practices, and risk perception. We show for the first time that the general population did not associate arsenic, which they perceive as toxic to health, with rice consumption. More than half of the participants knew about arsenic as a hazardous substance but less than ten percent knew that rice consumption could be an important route of arsenic exposure. Knowledge of arsenic was significantly lower in Asian/Asian British:Pakistanis (Pakistani) (OR: 0.006; 95\% $\mathrm{Cl}: 0.00-0.03$ ) and Asian/Asian British:Bangladeshis (Bangladeshi) (OR: 0.064; 95\% Cl:0.01-0.25) compared to White:English/Welsh/Scottish/Northern Irish/British (White British). Moreover, Bangladeshis consumed three times more rice (OR: 2.92; 95\% Cl:1.73-4.93) compared to White British. Overall higher rice consumption was not associated with higher knowledge of the nutritional value of rice. Rinsing rice before cooking, an effective arsenic removal technique, was practised by $93 \%$ of the participants; however, the most popular cooking method was the use of adequate water (rice to water ratio of 1:2) but not excess water (rice to water ratio of $>1: 4$ ), the latter being more effective in removing arsenic. Better education, higher weekly expenditure on food and prior knowledge of arsenic hazard were all significant factors positively influencing a change in behaviour to reduce arsenic exposure from rice intake.
\end{abstract}

\footnotetext{
${ }^{1}$ School of Science, Engineering \& Environment, University of Salford, Salford M5 4WT, UK. ${ }^{2}$ School of Earth and Environmental Sciences and Williamson Research Centre for Molecular Environmental Science, University of Manchester, Manchester M13 9PL, UK. ${ }^{3}$ School of Health and Society, University of Salford, Salford M5 4WT, UK. Correspondence and requests for materials should be addressed to D.M. (email: d.mondal@salford.ac.uk)
} 


\section{Introduction}

ice is a staple food for more than half of the world's population, especially in Asia, Africa and some Latin American countries. Although per capita rice consumption in the UK is relatively low, there has been an increase in its consumption due to its palatability, low allergenic potential, food diversification, and immigration (Schenker, 2012). Mean weekly rice consumption in the UK between 2016 and 2017 was around $90 \mathrm{~g} /$ week with this figure being much higher for various ethnic groups. Bangladeshi communities are by far the largest per capita rice consumers in the UK (Statista, 2019; Cascio et al., 2011).

Although rice is a source of nutrients such as carbohydrates, proteins, vitamins and minerals as well as being a source of dietary fibre (Schenker, 2012), it is also a major route of inorganic arsenic exposure (Adomako et al., 2009; Mondal et al., 2010; Mondal and Polya, 2008). Rice typically contains higher inorganic arsenic concentrations than other grains such as wheat and barley (Davis et al., 2017; Su et al., 2010). Arsenic is a class I carcinogen and can cause skin, bladder, liver, renal and lung cancer in humans (International Agency for Research on Cancer, 2012; Lynch et al., 2017). Other health risks include skin lesions, abdominal pain, diarrhoea, diabetes, hypertension, poor mental development, respiratory disorders and cardiovascular diseases (Naujokas et al., 2013), hence making it a public health concern. Emerging studies indicate arsenic exposure from rice consumption can lead to detrimental health effects, such as genotoxicity, as was suggested by elevated urothelial cell micronuclei frequency in a study population in West Bengal, India consuming cooked rice with arsenic greater than $200 \mu \mathrm{g} / \mathrm{kg}$ (Banerjee et al., 2013). Moreover, direct evidence of arsenic in rice related exposure is well explored in the review by Davis et al. (2017) signifying intake of rice to be associated with increased urinary arsenic across several studies. Relationship between rice consumption with arsenic biomarkers was clearly demonstrated in few other studies such as positive association between steamed rice consumption with total urinary arsenic and prevalence of skin lesions in Bangladesh (Melkonian et al., 2013); increase in urinary arsenic species with increased consumption of rice in NHANES study (deCastro et al., 2014); positive association between rice consumption and urinary arsenic excretion in US pregnant women (Gilbert-Diamond et al., 2011); and association between maternal rice consumption during pregnancy with infant toenail total arsenic indicating that dietary exposure from rice during pregnancy resulted in fetal exposure (Davis et al., 2014). With billions of people consuming rice as a staple food across the world and several percent of this rice containing elevated arsenic concentrations (Banerjee et al., 2013), populations not exposed to arsenic from contaminated water (e.g., in the UK) can be exposed to inorganic arsenic via consumption of rice. To date, there has been no study investigating public risk perception of arsenic exposure from rice intake. While this is of greater significance in countries with rice dominated diet and with high arsenic concentrations in rice due to cultivation with arsenic contaminated water, such as in South and Southeast Asia, understanding rice eating habits and knowledge of arsenic exposure from rice in countries such as in UK, where intake of rice for certain ethnic groups is very high (Cascio et al., 2011), is of equal importance.

Due to concerns about health risks from arsenic exposure as a result of food consumption, in 2010, the Joint FAO/WHO Expert Committee on Food Additives (JECFA) recommended an upper limit of $3 \mu \mathrm{g} / \mathrm{kg}$ bw/day for inorganic arsenic exposure using the benchmark dose lower confidence limit for a $0.5 \%$ (BMDL0.5) increased incidence of lung cancer. This replaced the former limit of $15 \mu \mathrm{g} / \mathrm{kg}$ bw/day. Furthermore, the European Food Safety Authority (EFSA) recommended a range between $0.3-8 \mu \mathrm{g} / \mathrm{kg}$ bw/day of inorganic arsenic exposure based on $1 \%$ increased incidence in lung, skin and bladder cancer and skin lesions (Cubadda et al., 2017). In 2014, JECFA recommended a maximum level of $200 \mu \mathrm{g} / \mathrm{kg}$ of inorganic arsenic in polished rice (white rice) and $400 \mu \mathrm{g} / \mathrm{kg}$ for brown rice (EFSA, 2014), however, as the recommendation is nonbinding, this is not enacted through regulation in many countries, with the notable exceptions of China and the countries of the European Union. Additionally, in line with recent changes in European Union directives, the UK Food Standard Agency recommended the maximum permissible level of $300 \mu \mathrm{g} / \mathrm{kg}$ of inorganic arsenic in rice-based products, while for infants and young children the limit was set at $100 \mu \mathrm{g} / \mathrm{kg}$ (FSA, 2018).

The arsenic content of cooked rice depends on many factors including rice variety (Islam et al., 2016), the region where it is grown (Adomako et al., 2009), irrigation method (Islam et al., 2016), and cooking method (Mandal et al., 2019; Mwale et al., 2018). Thus, for consumers in the UK, useful techniques for reducing inorganic arsenic exposure include (i) selection of rice varieties with low inorganic arsenic and (ii) the use of appropriate simple cooking methods, including the use of excess water and water with low arsenic content for cooking (Mwale et al., 2018). BBC News (2017) report 'Should I worry about arsenic in my rice?', the British Nutrition Foundation (2017) and Consumerreports (2012) give some relevant information on limiting arsenic exposure from rice and rice-based products, whilst the Food Standards Agency (2018) provides advice with respect to the use of rice milk for children under the age of five years. In addition to the availability of clear and appropriate authoritative advice, the adoption of appropriate change in rice eating habits to reduce exposure to inorganic arsenic is largely determined by consumer awareness, behaviour and risk perception (Coi et al., 2016).

The aim of this study therefore was to determine the level of knowledge of arsenic as an environmental risk, amongst different rice-eating ethnic communities of Greater Manchester and whether or not this knowledge had an influence on behaviour in relation to consumption and/or preparation of rice. To the best of our knowledge, this is the first study on risk perception of rice as a potential source for arsenic exposure in the UK.

\section{Methods}

Survey design. A questionnaire survey was conducted between December 2016 and April 2017. The study sites were chosen with the help of the 2011 Census data obtained from Manchester City Council Intelligence Hub (Council, 2019). Wards containing a high percentage of ethnic minorities were selected to ensure $50 \%$ of targeted participants in the survey were from high rice-eating ethnic groups. Moss Side was selected for the Black/African/ Caribbean/Black British (African/Caribbean), and Longsight for Asian/Asian British: Bangladeshi (Bangladeshi), and Asian/Asian British: Pakistani (Pakistani) populations, participation from those sites was restricted to these three ethnicities. Finally, Moston was selected for White: English/Welsh/Scottish/Northern Irish/ British (White British) as a comparison group. Volunteers were recruited from community centres, markets, mother and toddler groups, restaurants and places of worship. Permission was sought from the person in charge of each selected location and the date of survey was agreed. On the day of the survey, participants visiting the locations were presented with an information sheet and a consent form before the questionnaire was administered. Only those adult participants who gave informed consent and belonged to any of the four ethnic groups as specified above took part in the survey. The study was approved by the University of Salford Ethics Committee. All experiments were performed in accordance with relevant guidelines and regulations. 
Data collection. A pilot survey was carried out to determine the clarity, suitability of terminology, and average time required for completion of the questionnaire. Based on the preliminary data from the pilot study, modifications were carried out to improve the efficacy of the survey. The questionnaire survey was then administered, typically taking approximately $25-30-\mathrm{min}$ to complete per volunteer. Data were collected by three researchers, each at different times during the survey period.

The questionnaire included demographic information (age, gender, ethnicity, education, occupation, housing, weekly expenditure on food, use of different media); questions on (a) knowledge of arsenic; (b) benefits of rice consumption; (c) amount of rice consumption; (d) consumption of other grain and pulses; (d) rice preparation practices; and (e) risk perception (Table S1).

Data analysis. Descriptive statistics including frequency and association between variables using $\chi^{2}$ cross tabulation, $t$-test, and Fisher's exact test were used to characterise the studied population. The dependent/outcome variables examined were (a) rice consumption; (b) cooking practices (both rinsing and rice to water ratio for cooking); and (c) risk perception (perceived change towards rice consumption as a result of this survey).

A generalised linear model (GLM) was used to determine the factors potentially associated with the outcome variable. Appropriate functions were used to generate the best fitting model predicting the outcome using step wise forward regression. Multivariate GLM was used to determine the covariate adjusted association between the independent variables: (a) knowledge of arsenic (risk) and (b) nutritional knowledge of rice (benefit) and the outcome variables. The first step was to calculate the contribution of the independent variables (crude model) and then the second step was to include additional factors: gender, age, education, occupation, use of media, type of housing, consumption of other grains, and expenditure on food (adjusted) in order to assess the improvement to the overall prediction, and association of each of those factors to the best fitting model. Akaike's Information Criterion (AIC) and model deviance values were used to select the best-fitted linear model. R statistical software, version 3.4.3 (R Foundation for Statistical Computing) and STATA 11.2 (StataCorp, 2011) were used for the data analysis.

\section{Results and discussion}

Characterisation of survey participants by ethnic groups. A total of 184 participants took part in the survey, of which $59 \%$ were 'non-White British'(Asian/Asian British: Pakistani, Asian/ Asian British: Bangladeshi and/or Black/African/Caribbean/Black British: African/Caribbean).We found significant differences in demographic parameters and rice eating habits among the four ethnic groups (Table 1).

Knowledge of arsenic (Risk) and nutritional knowledge of rice (Benefit). When the participants were asked 'if they had ever heard of arsenic', $56 \%(n=103)$ answered in the affirmative and all confirmed that they 'believe arsenic is toxic to human health'. Being male, older, living as a tenant compared to being a house owner, and having higher education attainment were all significantly associated with greater knowledge of arsenic risks (Table 2).

There was greater awareness of arsenic risk in the White British volunteers (92\%) than for the non-White British (31\%). Of those who had heard of arsenic, only $12 \%(n=12$ out of 103$)$ said "yes" when asked 'if they believe that it is possible for humans to have arsenic exposure from rice intake'. Due to such a low number, all analysis on arsenic knowledge was restricted to knowing about arsenic rather than knowing rice to be a potential route of arsenic exposure. The Pakistani ethnic group had the highest percentage (89\%) of participants who had never heard of arsenic, followed by the Bangladeshis (58\%) and compared to White British, both ethnic groups had significantly lower knowledge of arsenic risks (Table 2). The only significant factor associated with nutritional knowledge of rice was the use of media, with participants using media substantially were three times more likely to know the nutritional benefits of rice.

Rice consumption behaviour and cooking practices. White British were found to consume a greater amount of rice per serving but at a lower frequency compared to the combined ethnic group. At the time of the survey there was no Food Standards Agency guideline on rice consumption in the UK, but the Swedish National Food Agency advises consumers to limit adult consumption of rice and rice-based products to six times a week (Ankarberg et al., 2015). Over $80 \%$ of the Bangladeshi participants were consuming just rice over this recommended frequency (Table 1) and their daily rice intake was found to be three times (95\% CI 1.73-4.93) that of White British. Using data from the DEFRA Expenditure and Food Survey, Meharg and Zhao (2012) also found that Asian-Bangladeshi are the largest consumer of rice in UK, purchasing over 30 times more rice than the average White British person. Whilst there is agreement between the two studies qualitatively, the quantitative differences may reflect one or more of (i) increased rice consumption in White British between 2012 and 2017; and (ii) the urban White British volunteers surveyed in the current study not being wholly representative of the UK wide White-British population.

The rice variety consumed by most of the participants was basmati rice (81\%). On the other hand, only $3 \%$ of the surveyed population reported consuming wild rice, which was the least consumed variety. Most (64\%) of the participants purchased their rice from local supermarkets whilst 59\% purchased theirs from African or Asian shops, some of which were also local supermarkets. Of vegetables, meat, fish, milk and 'other', the most popular rice accompaniment was meat whilst the least was milk.

Based on the crude model the percentage contribution of different independent variables on the overall variability of rice consumption were: age $(8.1 \%, p=<0.001)$, occupation $(6.3 \%$, $p=<0.001)$, ethnicity $(6.1 \%, p=<0.001)$, housing $(4.4 \%$, $p=0.003)$, and education $(2.6 \%, p=0.024)$. After adjusting for covariates, rice intake was found to be significantly higher in Bangladeshis, participants living as tenants or in other places over house owner, and those employed compared to unemployed (Table 3).

Rinsing the rice before cooking was practiced by $93 \%$ of the participants (Table 1). Washing rice before cooking can effectively remove around $10 \%$ of the total and inorganic arsenic from basmati rice but is less effective for other rice types (Raab et al. 2009). Based on the crude model, intake of other grains $(5.6 \%, p=0.025)$, arsenic knowledge $(5.4 \%, p=0.026)$, education $(4.1 \%, p=0.056)$, and expenditure on food $(4.0 \%, p=0.056)$ were found to be significantly associated with rice rinsing but none of the factors were found to be significantly associated in the adjusted model. While $18 \%$ of the White British said they prefer to cook rice without rinsing, this was significantly different in non-White British communities who prefer to wash rice before cooking with less than $1 \%$ of these participants cooking rice without rinsing. The most popular rice cooking method was the use of rice to water in a ratio of $1: 2$, practiced by $74 \%$ of White British and $67 \%$ of the non-White British, while the use of excess water, 


\section{Table 1 Differences in socio-demographic variables between the four ethnic groups}

\begin{tabular}{|c|c|c|c|c|c|c|c|}
\hline Demographic Variable & $\begin{array}{l}\text { White: English/Welsh/ } \\
\text { Scottish/ Northern } \\
\text { Irish/ British }(n=75)\end{array}$ & $\begin{array}{l}\text { Asian/Asian } \\
\text { British: Pakistani } \\
(n=62)\end{array}$ & $\begin{array}{l}\text { Asian/Asian British: } \\
\text { Bangladeshi }(n=31)\end{array}$ & $\begin{array}{l}\text { Black/African/ } \\
\text { Caribbean/Black } \\
\text { British }(n=16)\end{array}$ & $\begin{array}{l}\text { non-White } \\
\text { British }^{\mathrm{a}}(n=109)\end{array}$ & Total $(n=184)$ & $p$ value $^{b}$ \\
\hline $\begin{array}{l}\text { Age: Mean years } \\
\text { (standard deviation) }\end{array}$ & $48.6(12.8)$ & $38.6(12.6)$ & $40.8(14.1)$ & $53.8(16.1)$ & $41.4(14.4)$ & $44.4(14.2)$ & $<0.001^{c}$ \\
\hline \multicolumn{8}{|l|}{ Gender: Percentage ${ }^{d}$ (Count) } \\
\hline Male & $45.3(34)$ & $40.3(25)$ & $16.1(5)$ & $25.0(4)$ & $31.2(34)$ & $37.0(68)$ & \multirow[t]{3}{*}{0.025} \\
\hline Female & $54.7(41)$ & $59.7(37)$ & $83.9(26)$ & $75.0(12)$ & $68.8(75)$ & $63.0(116)$ & \\
\hline \multicolumn{7}{|l|}{$\begin{array}{l}\text { Education: Percentage } \\
\text { (Count) }\end{array}$} & \\
\hline Primary & $10.7(8)$ & $22.5(14)$ & $32.3(10)$ & $18.8(3)$ & $18.0(18)$ & $19.0(35)$ & \multirow[t]{4}{*}{0.002} \\
\hline Secondary & $66.7(50)$ & $40.3(25)$ & $25.8(8)$ & $37.5(6)$ & 39.0 (39) & $48.4(89)$ & \\
\hline Higher Education & $22.7(17)$ & $37.1(23)$ & 41.9 (13) & $43.8(7)$ & $43.0(43)$ & $32.6(60)$ & \\
\hline (College/University) & & \multicolumn{5}{|c|}{$\begin{array}{l}\text { Housing: Percentage } \\
\text { (Count), missing value }=1\end{array}$} & \\
\hline House owner & $33.3(25)$ & $47.5(29)$ & $38.7(12)$ & $25.0(4)$ & $41.7(45)$ & $38.3(70)$ & \multirow{2}{*}{0.258} \\
\hline Tenant and Others & $66.7(50)$ & $52.5(32)$ & $61.3(19)$ & $75.0(12)$ & $58.3(63)$ & $61.7(113)$ & \\
\hline \multicolumn{8}{|l|}{$\begin{array}{l}\text { Occupation: Percentage } \\
\text { (Count) }\end{array}$} \\
\hline Self employed & $32.0(24)$ & $41.9(26)$ & $6.5(2)$ & $0.0(0)$ & $25.7(28)$ & $28.3(52)$ & \multirow[t]{3}{*}{$<0.001$} \\
\hline Employed & $30.7(23)$ & $19.4(12)$ & $22.6(7)$ & $37.5(6)$ & $22.9(25)$ & $26.1(48)$ & \\
\hline Unemployed & $37.3(28)$ & $38.7(24)$ & $71.0(22)$ & $62.5(10)$ & $51.4(56)$ & $45.7(84)$ & \\
\hline \multicolumn{8}{|l|}{$\begin{array}{l}\text { Average weekly spending } \\
\text { on food: \% (Count) }\end{array}$} \\
\hline$<\notin 20$ & $13.3(10)$ & $21.0(13)$ & $16.1(5)$ & $18.8(3)$ & $19.2(21)$ & $16.8(31)$ & \multirow[t]{3}{*}{0.016} \\
\hline$€ 20-£ 50$ & $70.7(53)$ & $40.3(25)$ & $54.8(17)$ & $68.8(11)$ & $48.6(53)$ & $57.6(106)$ & \\
\hline$>£ 50$ & $16.0(12)$ & $38.7(24)$ & $29.0(9)$ & $12.5(2)$ & $32.2(35)$ & $25.5(47)$ & \\
\hline \multicolumn{8}{|l|}{$\begin{array}{l}\text { Rice consumption } \\
\text { frequency per week: }\end{array}$} \\
\hline \multicolumn{8}{|l|}{ Percentage (Count) } \\
\hline $\begin{array}{l}\text { Up to six times a week } \\
\text { (recommended)e }\end{array}$ & $98.7(74)$ & $96.8(60)$ & $19.4(6)$ & $93.8(15)$ & $74.3(81)$ & $84.2(155)$ & \multirow[t]{2}{*}{$<0.001$} \\
\hline More than six & $1.3(1)$ & $3.2(2)$ & $80.6(25)$ & $6.2(1)$ & $25.7(28)$ & $15.8(29)$ & \\
\hline times a week & & & & & & & \\
\hline \multirow{2}{*}{\multicolumn{8}{|c|}{$\begin{array}{l}\text { Amount of rice } \\
\text { consumption each time: } \\
\text { Percentage (Count), } \\
\text { missing = } 1\end{array}$}} \\
\hline & & & & & & & \\
\hline Less than 1 cup ( $200 \mathrm{~g}$ ) & $13.3(10)$ & $24.6(15)$ & $35.5(11)$ & $31.3(5)$ & $28.7(31)$ & \multirow{2}{*}{$\begin{array}{l}22.4(41) \\
47.0(86)\end{array}$} & $0.042^{f}$ \\
\hline 1 cup & $50.7(38)$ & $39.3(24)$ & $51.6(16)$ & $50.0(8)$ & $44.4(48)$ & & \\
\hline 2 cups or more & $36.0(27)$ & $36.1(22)$ & $12.9(4)$ & $18.7(3)$ & $26.9(29)$ & $30.6(56)$ & \\
\hline $\begin{array}{l}\text { Rinsing: Percentage } \\
\text { (Count), missing }=8\end{array}$ & & & & & & & \\
\hline Yes & $82.1(55)$ & $100.0(62)$ & $100.0(31)$ & $93.8(15)$ & $99.1(108)$ & $92.6(163)$ & $<0.001$ \\
\hline No & $17.9(12)$ & $0.0(0)$ & $0.0(0)$ & $6.3(1)$ & $0.9(1)$ & $7.4(13)$ & \\
\hline Rice to water ratio: & & & & & & & \\
\hline $\begin{array}{l}\text { Percentage (Count) } \\
\text { missing }=14\end{array}$ & & & & & & & \\
\hline 1: 1 (limited water) & $6.1(4)$ & $17.2(10)$ & $3.3(1)$ & $25.0(4)$ & $14.4(15)$ & $11.2(19)$ & $0.044^{f}$ \\
\hline $\begin{array}{l}\text { 1: } 2 \text { (required amount } \\
\text { of water) }\end{array}$ & $74.2(49)$ & $62.1(36)$ & $73.3(22)$ & $75.0(12)$ & $67.3(70)$ & 70.0 (119) & $18.8(32)$ \\
\hline$>1: 4$ (excess water) & 19.7 (13) & $20.7(12)$ & $23.3(7)$ & $0.0(0)$ & $18.3(19)$ & & \\
\hline Inherited cooking & & & & & & & \\
\hline $\begin{array}{l}\text { practices: Percentage } \\
\text { (Count), missing =7 }\end{array}$ & & & & & & & \\
\hline Yes & $78.6(55)$ & $96.7(58)$ & $90.3(28)$ & $87.5(14)$ & $93.5(100)$ & $87.6(155)$ & 0.019 \\
\hline No & $21.4(15)$ & $3.3(2)$ & $9.7(3)$ & $12.5(2)$ & $6.5(7)$ & $12.4(22)$ & \\
\hline Rice consumption at: & & & & & & & \\
\hline Percentage (Count) & & & & & & & \\
\hline Breakfast & $5.7(4)$ & $6.7(4)$ & $0.0(0)$ & $7.1(1)$ & $4.9(5)$ & $5.2(9)$ & $<0.001$ \\
\hline Lunch & $24.6(17)$ & $26.3(15)$ & $80.6(25)$ & $64.3(9)$ & $48.0(49)$ & $38.6(66)$ & \\
\hline Dinner & $60.3(44)$ & $48.4(30)$ & $77.4(24)$ & $81.3(13)$ & $61.5(67)$ & $61.0(111)$ & \\
\hline $\begin{array}{l}\text { Consumption of other } \\
\text { grains: Percentage }\end{array}$ & & & & & & & \\
\hline $\begin{array}{l}\text { (Count) } \\
\text { Yes }\end{array}$ & & & & & & & \\
\hline $\begin{array}{l}\text { Yes } \\
\text { No }\end{array}$ & $84.0(63)$ & $79.0(49)$ & $77.4(24)$ & $87.5(14)$ & $79.8(87)$ & $81.5(150)$ & 0.759 \\
\hline $\begin{array}{l}\text { No } \\
\text { Substantial use of Mediag. }\end{array}$ & $16.0(12)$ & $21.0(13)$ & $22.6(7)$ & $12.5(2)$ & $20.2(22)$ & $18.5(34)$ & \\
\hline $\begin{array}{l}\text { Substantial use of Mediag: } \\
\text { Percentage (Count) }\end{array}$ & & & & & & & \\
\hline Low use & $48.0(36)$ & $75.8(47)$ & $58.1(18)$ & $50.0(8)$ & $67.0(73)$ & $59.2(109)$ & 0.007 \\
\hline High use & $52.0(39)$ & $24.2(15)$ & 41.9 (13) & $50.0(8)$ & $33.0(36)$ & $40.8(75)$ & \\
\hline Knowledge of arsenic: & & & & & & & \\
\hline Percentage (count) & & & & & & & \\
\hline Yes & $92.0(69)$ & $11.3(7)$ & 41.9 (13) & $87.5(14)$ & $31.2(34)$ & $56.0(103)$ & $<0.001$ \\
\hline No & $8.0(6)$ & $88.7(55)$ & $58.1(18)$ & $12.5(2)$ & $68.8(75)$ & $44.0(81)$ & \\
\hline
\end{tabular}

aThe Pakistani, Bangladeshi and African/Caribbean were combined to form one group, referred to as 'non-White British'

bFisher's exact test (testing the significant differences between the frequency distribution of categorial variables among the four ethnic groups)

cOne-way ANOVA (testing the significant differences between the mean age of the four ethnic groups)

dPercentage in parentheses by column

eRecommended by Swedish National Food Agency (Ankarberg et al., 2015)

${ }^{f}$ Not significant if Pearson $\mathrm{Chi}^{2}$ test is used

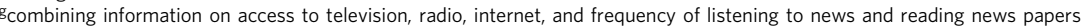


Table 2 Factors associated with general arsenic knowledge and knowledge of nutritional value of rice

\begin{tabular}{|c|c|c|c|c|c|c|}
\hline \multirow[b]{2}{*}{ Factors } & \multicolumn{3}{|c|}{ Arsenic knowledge } & \multicolumn{3}{|c|}{ Knowledge of nutritional value of rice } \\
\hline & Odds Ratio & $95 \% \mathrm{Cl}$ & $p$ & Odds Ratio & $95 \% \mathrm{Cl}$ & $p$ \\
\hline Age & 1.06 & 1.01-1.11 & 0.005 & 0.98 & $0.94-1.01$ & 0.275 \\
\hline \multicolumn{7}{|l|}{ Gender (Reference: Male) } \\
\hline Female & 0.24 & $0.06-0.88$ & 0.031 & 0.79 & $0.29-2.12$ & 0.644 \\
\hline \multicolumn{7}{|c|}{ Ethnicity (Reference: White: English/Welsh/Scottish/Northern Irish/ British) } \\
\hline Asian/Asian British: Pakistani & 0.006 & $0.00-0.03$ & $<0.001$ & 1.23 & $0.44-3.45$ & 0.685 \\
\hline Asian/Asian British: Bangladeshi & 0.064 & $0.01-0.25$ & $<0.001$ & 0.46 & $0.13-1.51$ & 0.203 \\
\hline Black/African/ Caribbean/Black British & 0.291 & $0.04-1.97$ & 0.207 & 2.05 & $0.37-11.10$ & 0.405 \\
\hline $\begin{array}{l}\text { Housing (Reference: house owner) Tenants } \\
\text { and others }\end{array}$ & 3.70 & $1.12-12.18$ & 0.031 & 0.71 & $0.29-1.75$ & 0.466 \\
\hline \multicolumn{7}{|l|}{ Occupation (Reference: Unemployed) } \\
\hline Self employed & 0.89 & $0.18-4.31$ & 0.893 & 1.02 & $0.33-3.12$ & 0.965 \\
\hline Employed & 2.09 & $0.57-7.65$ & 0.261 & 1.70 & $0.55-5.19$ & 0.349 \\
\hline \multicolumn{7}{|l|}{ Education (Reference: primary) } \\
\hline Secondary & 1.45 & $0.34-6.17$ & 0.608 & 0.38 & $0.11-1.38$ & 0.144 \\
\hline Higher & 12.27 & 2.44-61.70 & 0.002 & 0.38 & $0.10-1.39$ & 0.146 \\
\hline Media use (Reference: low) High & 0.95 & $0.33-2.72$ & 0.922 & 3.64 & $1.42-9.31$ & 0.007 \\
\hline
\end{tabular}

Odds Ratio determined using GLM with binomial family and logit link function; for Arsenic Knowledge: $A I C=133$; Deviance/df $=0.64, N=183$; For Knowledge of nutritional value of rice: AIC $=187$; Deviance $/ \mathrm{df}=0.99, \mathrm{~N}=176$

Bold values indicates statistically significant results compared to other factors

Table 3 Factors associated with rice consumption behaviour

\begin{tabular}{|llll} 
& \multicolumn{3}{c}{ Daily Rice consumption (g) } \\
\cline { 2 - 4 } & IRR & $\mathbf{9 5 \%} \mathbf{~ C l}$ & p value \\
\hline Arsenic knowledge & 0.77 & $0.51-1.15$ & 0.202 \\
Knowledge of nutritional value & 1.24 & $0.82-1.88$ & 0.295
\end{tabular}

of rice

Ethnicity (Reference: White: English/Welsh/Scottish/Northern Irish/ British)

Asian/Asian British: Bangladeshi $\quad \mathbf{2 . 9 2} \quad \mathbf{1 . 7 3 - 4 . 9 3}<\mathbf{0 . 0 0 1}$

Black/African/ Caribbean/Black $1.00 \quad 0.55-1.82 \quad 0.999$

British

Housing (Reference: house owner)

Tenants and others 1.98

Self employed 1.46

Employed

2.11

$1.40-2.81$

$<0.001$

Education (Reference: primary)

Secondary

Higher

0.69

0.96

Significant use of media (Reference No)

Substantial use of media $\quad 1.22$

Age

0.99

$0.97-2.22$

0.069

1.40-3.18

$<0.001$

$0.44-1.06$

0.096

$0.59-1.55$

0.861

$0.86-1.75 \quad 0.265$

$0.98-1.01 \quad 0.442$

Incidence rate ratio (IRR) determined using GLM with negative binomial family and log link function

AIC = 2000; Deviance $/ \mathrm{df}=1.13, \mathrm{~N}=175$

Bold values indicates statistically significant results compared to other factors

which can remove between 15 to $63 \%$ of rice arsenic (Mwale et al. 2018), was less popular. There was no particular factor significantly associated with cooking behaviour but compared to White British (79\%) a higher percentage of non-White British participants (94\%) revealed that their rice cooking practices were inherited (Table 1), even though cooking in excess water is widely practised in Bangladesh and Africa (Mwale et al. 2018).

Apart from rice consumption, the participants were also asked about consumption of other rice-based products. The most popular rice-based product consumed by $39 \%$ of the participants (at least once a day), was crisped rice. In a UK market-based study, total arsenic concentrations in crisped rice was found to be high (average $210 \mu \mathrm{g} / \mathrm{kg}$ ), with a high percentage of inorganic arsenic (86\%) content (Sun et al., 2009). Hence, cumulative arsenic exposure from both rice and rice-based products in this studied population is of concern.

Risk perception and attitudes towards changing rice eatinghabit. This study also investigated any change in attitude towards reduced rice consumption as a result of the survey, which clearly communicated some possible risk of detrimental arsenic exposure from rice intake to the participants during the 30 -min questionnaire survey. Only $29 \%$ of the participants mentioned any one of the potential changes, such as consuming less (quantity or frequency) rice or consuming other grains instead of rice. According to Rundmo and Nordfjaern (2017), knowledge of the hazard determines risk perception and behaviour and it is not primarily the risk, but the risk source that is perceived. However, in this study, most participants did not associate arsenic, which they perceive as toxic to health, with rice consumption; hence, perception of risk of arsenic exposure from rice consumption is low.

Food may simultaneously be associated with risks, such as exposure to contaminants, and benefits, such as nutritional advantages (Kaptan et al., 2017). We found those with arsenic knowledge were four times more likely to change and those with nutritional knowledge of rice were significantly $(62 \%)$ less likely to change their rice eating habit compared to those without the respective knowledge. Participants who spend more on food and with a higher education attainment were more likely to change. While $35 \%$ of White British said they would change their behaviour but when other ethnic groups were compared to White British (as reference) it was the African/Caribbean who were four times more likely to change (Table 4). Among theAfrican/ Caribbean participants $87 \%$ knew about arsenic, though the number of participants was low $(n=16)$. Both Pakistani (OR: 0.52; 95\% CI: 0.14-1.93) and Bangladeshi (OR: 0.71; 95\% CI: $0.20-2.51$ ) participants were less likely to change their rice eating habit compared to White British. Though knowledge of arsenic was significantly higher in participants with higher educational attainment (OR: 12.27; 95\% CI: 2.44-61.70), overall, rice consumption was independent of educational status and knowledge of arsenic as a hazard. Hence, factors assumed to be important in the conceptualisation of risk perception may not be a fruitful basis for understanding how people perceive risks and 
Table 4 Factors associated with change in attitude towards rice consumption due to this survey

\begin{tabular}{|llll} 
Factors & Odds Ratio & $\mathbf{9 5 \%} \mathbf{C l}$ & $\boldsymbol{p}$ \\
\hline Arsenic knowledge & $\mathbf{4 . 5 2}$ & $\mathbf{1 . 7 8 - 1 1 . 5 3}$ & $\mathbf{0 . 0 0 2}$ \\
Knowledge of nutritional value & $\mathbf{0 . 3 8}$ & $\mathbf{0 . 1 6}-\mathbf{0 . 8 9}$ & $\mathbf{0 . 0 2 5}$
\end{tabular}

of rice

Ethnicity (Reference: White: English/Welsh/Scottish/Northern Irish/

British)

$\begin{array}{llll}\text { Asian/Asian British: Pakistani } & 0.52 & 0.14-1.93 & 0.334\end{array}$

$\begin{array}{llll}\text { Asian/Asian British: } & 0.71 & 0.20-2.51 & 0.602\end{array}$

Bangladeshi

$\begin{array}{llll}\text { Black/African/ Caribbean/ } & \mathbf{3 . 9 7} & \mathbf{1 . 1 3}-13.9 & \mathbf{0 . 0 3 2}\end{array}$

$\begin{array}{llll}\text { Black British } & & & \\ \text { non-White British } & 1.33 & 0.53-3.32 & 0.539\end{array}$

Expenditure on food (Reference $<\notin 20$ )

Expenditure on food $(£ 20-£ 50) \quad \mathbf{3 . 7 4}$

Expenditure on food ( $>E 50) \quad \mathbf{4 . 9 0}$

Education (Reference: primary)

Secondary 3.09

Higher $\quad \mathbf{5 . 3 2}$

(ence: twice a week or less)

$\begin{array}{llll}\text { More than twice a week } & 1.97 & 0.91-4.25 & 0.082\end{array}$

Model: GLM with binomial family and logit link function; $N=177 ; \mathrm{AIC}=195.8$ : Deviance/ $\mathrm{df}=1.05$

Bold values indicates statistically significant results compared to other factors

measures aimed at influencing perceptions of risk should to a larger extent take into consideration how such risks are perceived (Rundmo and Nordfjaern, 2017).

Because food has cultural, symbolic, familial, and religious connotations, complete avoidance of food risks is not possible (Kaptan et al., 2017). Furthermore, familiarity decreases consumers' feelings of uncertainty and increases perceived control towards a food product and the benefits of a food product are more significant in the mind of a consumer than risks (Jacobs et al., 2015). For example, a participant mentioned that 'she has been eating rice since she was a child and she has not had any health issues because of rice. Therefore, she does not think there is any health risk associated with rice consumption'. This could also be due to the predisposition of people to believe that they are less vulnerable to particular risks as perception of personal exposure to any hazard is higher in geographical areas characterised by anthropogenic or geogenic pollution (Coi et al., 2016), as in arsenic endemic areas. Thus "perception of benefit is based on heuristics (easy decisions and simple intuitive strategies) whereas risk perception is based on cognitive or rational information processing" (Ueland et al., 2012). Besides, there are perceived health benefits of rice consumption over other food products outweighing the perceived risk of detrimental health effects arising from inorganic arsenic exposure from rice intake. Hence, clear, culturally appropriate, and participant engaged communication about this issue and ways to reduce risks, such as appropriate cooking techniques, is critical to help rice-eating communities lower health risks associated with the consumption of inorganic arsenic containing rice. This communication might ideally include more specific advice from the Food Standards Agency on recommended maximum weekly rice intake and information from wholesalers and retailers of rice and rice products as to the inorganic arsenic contents of their products.

Limitations. The main challenges to generalise our findings to UK or non-UK populations include (a) geographic and ethnic differences in study populations (we have already mentioned that the White British volunteers surveyed in the current study may not be wholly representative of the UK wide White British population); (b) difference in magnitude of the problem worldwide and hence factors controlling awareness among different populations; and (c) the influential role of culture and religion in selection of foods, for example, in Bangladesh people are proud of their diet consisting of rice and fish (Cascio et al., 2011).

In this study, participation, particularly from African/Caribbean and Bangladeshi ethnic groups was limited. This arguably highlights a limitation, in particular when stratification of a variable/factor was done. Although the population size of this study is relatively small, the statistically significant results, such as higher consumption by Bangladeshi populations, are consistent with previous studies (Cascio et al., 2011).

Though knowledge of arsenic exposure from rice intake as opposed to general arsenic knowledge could be a more appropriate factor for risk perception and willingness to change rice eating habit, the number of participants with knowledge of arsenic exposure from rice intake $(n=12)$ was very limited. That said, our study could be used to reflect how people might be expected to respond to more specific questions about knowledge of arsenic. Future studies could be aimed at using more deliberative approaches to allow for the provision of more information towards understanding of the factors contributing to the knowledge gap.

\section{Conclusions}

The overall aim of our study was to determine factors associated with knowledge of arsenic exposure from rice intake; rice consumption and cooking practices; and public perceptions of risks associated with exposure to arsenic in rice. Results based on the questionnaire survey of rice-eating communities of Greater Manchester, UK revealed, ethnicity as a factor strongly associated with observed differences in rice consumption, arsenic knowledge, and attitude towards changing rice-eating habits. It was Bangladeshi participants who consumed the highest amount of rice but, together with Pakistani participants, had significantly lower knowledge of arsenic and were less likely to change their rice eating habits compared to White British participants. A key finding of our study is that very few participants were aware of potential arsenic exposure from rice intake and that is reflected in a lack of willingness to change rice cooking and eating habits. In this survey, although $42 \%$ of Bangladeshi, $11 \%$ of Pakistani, $87 \%$ of African/Caribbean, and $92 \%$ of White British participants knew about arsenic toxicity, only seven Bangladeshi and five White British participants respectively knew about arsenic exposure from rice intake. Among those with knowledge of arsenic it was African/Caribbean (64\%) who were more likely to change their rice eating habits while $38 \%$ of Bangladeshi; $35 \%$ of White British and $14 \%$ of Pakistani were willing to change as a result of this survey. Better education, higher weekly expenditure on food and prior knowledge of arsenic hazard were positively associated with change in attitude towards rice consumption due to this survey.

Implications. This study provides a basis for further similar but larger population-based studies. It would be of great significance to determine if the factors associated with rice consumption behaviour, cooking practices, knowledge of arsenic and perception associated with exposure to arsenic in rice observed in our study are representative in populations in other countries. Besides, determining the difference in risk perception between countries, where there are recommendations or regulation limiting acceptable arsenic concentration in rice such as in Europe, with countries where high arsenic in rice prevails, and such regulations are not enacted such as in South and Southeast Asia will be of importance. 


\section{Data availability}

The datasets generated during and/or analysed during the current study are available from the corresponding author on reasonable request.

Received: 28 March 2019 Accepted: 9 July 2019

Published online: 06 August 2019

\section{References}

Adomako EE, Solaiman ARM, Williams PN, Deacon C, Rahman MM, Meharg AA (2009) Enhanced transfer of arsenic to grain for Bangladesh grown rice compared to US and EU. Environ Int 35:476-479

Ankarberg EH, Fogelberg P, Gustafsson K, Nordenfors H, Bjerselius R (2015) Inorganic arsenic in rice and rice products on the Swedish market 2015. National Food Agency, Sweden, pp 1-28

Banerjee M, Banerjee N, Bhattacharjee P, Mondal D, Lythgoe PR, Martínez M, Pan J, Polya DA, Giri AK (2013) High arsenic in rice is associated with elevated genotoxic effects in humans. Sci Rep 3:2195

BBC News (2017) Should I worry about arsenic in my rice? https://www.bbc.co.uk/ news/health-38910848.com. Accessed 7 July 2019

British Nutrition Foundation (2017) Arsenic in rice-is it a cause of concern? https://www.nutrition.org.uk/nutritioninthenews/headlines/arsenicinrice. html. Accessed 7 July 2019

Cascio C, Raab A, Jenkins RO, Feldmann J, Meharg AA, Haris PI (2011) The impact of a rice based diet on urinary arsenic. J Environ Monit 13:257-265

Coi A, Minichilli F, Bustaffa E, Carone S, Santoro M, Bianchi F, Cori L (2016) Risk perception and access to environmental information in four areas in Italy affected by natural or anthropogenic pollution. Environ Int 95:8-15

Consumerreports (2012) Arsenic in your food investigated-consumer reports. https://www.consumerreports.org/cro/magazine/2012/11/arsenic-in-yourfood/index.htm. Accessed 7 July 2019

Council (2019) Intelligence Hub | Intelligence Hub | Manchester City Council. https://www.manchester.gov.uk/info/200088/statistics_and_intelligence/ 7611/intelligence hub. Accessed 7 July 2019

Cubadda F, Jackson BP, Cottingham KL, Van Horne YO, Kurzius-Spencer M (2017) Human exposure to dietary inorganic arsenic and other arsenic species: State of knowledge, gaps and uncertainties. Sci Total Environ 579:1228-1239

Davis MA, Li Z, Gilbert-Diamond D, Mackenzie TA, Cottingham KL, Jackson BP, Lee JS, Baker ER, Marsit CJ, Karagas MR (2014) Infant toenails as a biomarker of in utero arsenic exposure. J Expo Sci Environ Epidemiol 24(5):467

Davis MA, Signes-Pastor AJ, Argos M, Slaughter F, Pendergrast C, Punshon T, Gossai A, Ahsan H, Karagas MR (2017) Assessment of human dietary exposure to arsenic through rice. Sci Total Environ 586:1237-1244

de Castro BR, Caldwell KL, Jones RL, Blount BC, Pan Y, Ward C, Mortensen ME (2014) Dietary sources of methylated arsenic species in urine of the United States population, NHANES 2003-2010. PloS ONE 9(9):e108098

EFSA (2014) Dietary exposure to inorganic arsenic in the European population. EFSA J 12:3597

Food Standards Agency (2018) Arsenic in rice. https://www.food.gov.uk/safetyhygiene/arsenic-in-rice. Accessed 7 July 2019

Gilbert-Diamond D, Cottingham KL, Gruber JF, Punshon T, Sayarath V, Gandolfi AJ, Baker ER, Jackson BP, Folt CL, Karagas MR (2011) Rice consumption contributes to arsenic exposure in US women. Proc Natl Acad Sci 108 (51):20656-20660

International Agency for Research on Cancer (2012) Arsenic, metals, Fibres, and dusts: a review of human carcinogens. vol 100, p. 527, IARC Monographs, WHO, Geneva, Switzerland

Islam S, Rahman MM, Islam MR, Naidu R (2016) Arsenic accumulation in rice: Consequences of rice genotypes and management practices to reduce human health risk. Environ Int 96:139-15

Jacobs S, Sioen I, Pienaiak Z, De Henauw S, Maulvault AL, Reuver M, Fait G, Cano-Sancho G, Verbeke (2015) Consumers' health risk-benefit perception of seafood and attitude toward the marine environment: Insights from five European countries. Environ Res 143:11-19

Kaptan G, Fischer ARH, Frewer LJ (2017) Extrapolating understanding of food risk perceptions to emerging food safety cases. J Risk Res 21:996-1018

Lynch HN, Zu K, Kennedy EM, Lam T, Liu X, Pizzurro DM, Loftus CT, Rhomberg LR (2017) Quantitative assessment of lung and bladder cancer risk and oral exposure to inorganic arsenic: meta-regression analyses of epidemiological data. Environ Int 106:178-206

Mandal U, Singh P, Kundu AK, Chatterjee D, Nriagu J, Bhowmick S (2019) Arsenic retention in cooked rice: Effects of rice type, cooking water, and indigenous cooking methods in West Bengal, India. Sci Total Environ 648:720-727
Meharg AA, Zhao FJ (2012) Risk from arsenic in rice grain. In: Arsenic \& Rice Springer, Dordrecht, pp. 31-50

Melkonian S, Argos M, Hall MN, Chen Y, Parvez F, Pierce B, Cao H, AschebrookKilfoy B, Ahmed A, Islam T, Slavcovich V (2013) Urinary and dietary analysis of 18,470 Bangladeshis reveal a correlation of rice consumption with arsenic exposure and toxicity. PloS ONE 8(11):e80691

Mondal D, Banerjee M, Kundu M, Banerjee N, Bhattacharya U, Giri AK, Ganguli B, Sen Roy S, Polya DA (2010) Comparison of drinking water, raw rice and cooking of rice as arsenic exposure routes in three contrasting areas of West Bengal, India. Environ Geochem Health 32:463-477. https://doi.org/10.1007/ s10653-010-9319-5

Mondal D, Polya DA (2008) Rice is a major exposure route for arsenic in Chakdaha block, Nadia district, West Bengal, India: A probabilistic risk assessment. Appl Geochem 23:2987-2998

Mwale T, Rahman MM, Mondal D (2018) Risk and benefit of different cooking methods on essential elements and arsenic in rice. Int J Environ Res Public Health 15:1-11

Naujokas MF, Anderson B, Ahsan H, Aposhian HV, Graziano JH, Thompson C, Suk WA (2013) The broad scope of health effects from chronic arsenic exposure: update on a worldwide public health problem. Environ Health Perspect 121:295-302

Raab A, Baskaran C, Feldmann J, Meharg AA (2009) Cooking rice in a high water to rice ratio reduces inorganic arsenic content. J Environ Monit 11:41-44

Rundmo T, Nordfjaern T (2017) Does risk perception really exist? Saf Sci 93:230-240

Schenker S (2012) Overv role rice UK diet Nutr Bull 37:309-323

StataCorp (2011) Stata Statistical Software: Release 11 StataCorp LP, College Station, TX

Statista (2019) Rice: Weekly consumption in the UK 2006-2016/17| https://www. statista.com/statistics/284474/weekly-household-consumption-of-rice-in-theunited-kingdom-uk/. Accessed 7 July 2019

Su Y, McGrath SP, Zhao F (2010) Rice is more efficient in arsenite uptake and translocation than wheat and barley. Plant Soil 328:27-34

Sun GX, Williams PN, Zhu YG, Deacon C, Carey AM, Raab A, Feldmann J, Meharg AA (2009) Survey of arsenic and its speciation in rice products such as breakfast cereals, rice crackers and Japanese rice condiments. Environ Int 35:473-475

Ueland O, Gunnlaugsdottir H, Holm F, Kalogeras N, Leino O, Luteijn JN, Magnusson SH, Odekerken G, Pohjola MV, Tijhuis MJ, Tuomisto JT, White BC Verhagen H (2012) State of the art in benefit-risk analysis: Consumer perception. Food Chem Toxicol 50:67-76

\section{Acknowledgements}

TM acknowledges receipt of Pathway to Excellence PhD scholarship from the University of Salford. This work was supported by a University of Manchester President's Doctoral Award to LX, a NERC India-UK Water Quality award ((NE/R003386/1) (FAR-GANGA) to DP and DM and a UKIERI award (IND/CONT/G/16-17/93) to DM and HM. We are grateful for the contribution of a Nuffield Trust sponsored student in the field survey.

\section{Additional information}

The online version of this article (https://doi.org/10.1057/s41599-019-0297-7) contains supplementary material, which is available to authorised users.

Competing interests: The authors declare no competing interests.

Reprints and permission information is available online at http://www.nature.com/ reprints

Publisher's note: Springer Nature remains neutral with regard to jurisdictional claims in published maps and institutional affiliations.

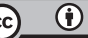

Open Access This article is licensed under a Creative Commons Attribution 4.0 International License, which permits use, sharing adaptation, distribution and reproduction in any medium or format, as long as you give appropriate credit to the original author(s) and the source, provide a link to the Creative Commons license, and indicate if changes were made. The images or other third party material in this article are included in the article's Creative Commons license, unless indicated otherwise in a credit line to the material. If material is not included in the article's Creative Commons license and your intended use is not permitted by statutory regulation or exceeds the permitted use, you will need to obtain permission directly from the copyright holder. To view a copy of this license, visit http://creativecommons.org/ licenses/by/4.0/.

(C) The Author(s) 2019 